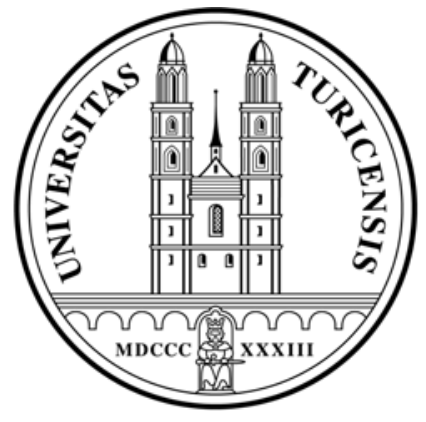

Institute for Empirical Research in Economics

University of Zurich

Working Paper Series

ISSN 1424-0459

Working Paper No. 387

Idiosyncratic Consumption Risk and Predictability of the Carry Trade Premium: Euro Area Evidence

Thomas Nitschka

September 2008 


\title{
Idiosyncratic Consumption Risk and Predictability of the Carry Trade Premium: Euro Area Evidence
}

\author{
Thomas Nitschka ${ }^{1}$ \\ Institute for Empirical Research in Economics, University of Zurich
}

\begin{abstract}
The empirical failure of the uncovered interest rate parity condition seems to be the reflection of risk premia on foreign currencies. After the formation of foreign currency portfolios according to interest rate differentials or forward discounts, recent studies suggest that either consumption- or currency return-based pricing factors explain the cross-section of foreign currency portfolio returns. The contribution of this paper is twofold. It shows that the returnbased explanation applies to foreign currency portfolios sorted from the perspective of a Euro Area investor. Secondly, the main results of this paper suggest that the decisive pricing factor, the so called carry trade premium, mirrors business cycle related risks. Times of relatively large amounts of uninsured Euro Area consumption growth risk are associated with an expected increase of the carry trade premium.
\end{abstract}

JEL: F31, G10, G15

Keywords: consumption risk sharing, foreign currency returns, return predictability, UIP

\footnotetext{
${ }^{1}$ E-mail: thomas.nitschka@iew.uzh.ch, Postal address: Chair of International Trade and Finance, Institute for Empirical Research in Economics, University of Zurich, Zurichbergstrasse 14, 8032 Zurich.

I am grateful to Mika Tujula and Bernhard Winkler for providing me with the Euro Area data sets used in this paper. Furthermore, I gratefully acknowledge financial support from the Fonds zur Förderung des Akademischen Nachwuchses (FAN) of the University of Zurich sponsored by the ecoscientia donation. Any errors are entirely mine.
} 


\section{Introduction}

Uncovered interest rate parity implies that currencies depreciate by the interest rate differential between the home and foreign country. Empirically, high interest rate currencies do not depreciate as much as expected from the difference between foreign and home interest rates and low interest rate currencies depreciate by more than expected from interest rate differentials (Fama (1984)). One possible explanation for this finding is that investors demand an extra risk premium for investments in foreign currencies (see e.g. the survey in Engle (1996)). If there is a risk premium in currency returns, then basic asset pricing theory should apply and explain such cross-sectional differences in foreign currency returns.

The first paper that provides an asset pricing based explanation is Lustig and Verdelhan (2007). After building portfolios of currencies according to their previous period's interest rate differential vis-à-vis the U.S., Lustig and Verdelhan (2007) show that a consumptionbased asset pricing model explains the cross-sectional dispersion in annual foreign currency excess returns. De Santis and Fornari (2008) confirm this observation for various other countries.

This paper builds on Lustig, Roussanov and Verdelhan (2008) who show that the currency portfolios themselves contain sufficient information to identify pricing factors that explain cross-sectional differences in the portfolio returns. Lustig et al. (2008) identify two factors. The first one is the average excess return on all currency portfolios, the second one the difference between the return on the highest interest rate portfolio minus the return on the lowest interest rate portfolio. The latter factor mimics the typical carry trade, borrowing in low interest rate countries and investing in high interest rate currencies. Exposure to this carry trade return explains the cross-section of foreign currency portfolio returns from the U.S., UK, Japanese and Swiss investor’s perspective. 
This paper's contribution is empirical and twofold. First, I show that the basic logic of the two factor model of Lustig et al. (2008) applies to the Euro Area in the time period from the first quarter of 1980 to the first quarter of 2007. Therefore, I follow Lustig and Verdelhan (2007) and form quarterly rebalanced foreign currency portfolios from the Euro Area perspective. High interest rates vis-à-vis the Euro Area signal high currency excess returns while low interest rates are associated with low currency excess returns. As in Lustig et al. (2008), differences in the exposure to the carry trade factor explain the cross-section of foreign currency portfolio returns under study.

Second, this paper tries to assess if the carry trade premium reflects macroeconomic risks. In particular, this study is focused on the implications of incomplete consumption risk sharing for asset risk premia (Lustig and van Nieuwerburgh (2005, 2006a,b)). In the theoretical framework of Lustig and van Nieuwerburgh (2005), a currently high level of uninsured consumption risk should be associated with an expected increase in the risk premium on asset markets.

Uninsured consumption risk is mirrored in the ratio of an economy's collateral to noncollateral wealth as households in this economy can only buffer their consumption streams from idiosyncratic income shocks through borrowing and lending. The availability of collateral, reflected in the ratio of collateral to non-collateral wealth, determines the tightness of borrowing constraints. Empirically, this collateral ratio is approximated by the ratio of housing to income. Short-run variation of the housing-income ratio echoes the temporary variation in the tightness of borrowing constraints and is hence closely related to the dispersion in consumption growth rates across households and regions in the economy (Lustig and van Nieuwerburgh (2006a,b)). Short-run variations in the collateral to non-collateral ratio should thus serve as predictor of asset risk premia. Lustig and van Nieuwerburgh (2005) for the U.S. and Nitschka (2008) for the Euro Area present evidence that this implication of the 
incomplete consumption risk sharing framework is fulfilled when the collateral to noncollateral ratio is approximated with housing-income ratios.

This paper assesses if the Euro Area housing-income ratio predicts the two factors of the Euro Area version of the Lustig et al. (2008) model under study. The results are unambiguous. A temporarily high housing-income ratio, i.e. times of relatively little uninsured consumption risk, signals a low return on the carry trade factor at the business cycle frequency. This finding clearly suggests that the decisive factor in explanations of the cross-section of excess returns on foreign currencies mirrors macroeconomic risks.

As a robustness check I also sort currency excess returns according to their exposure to shortrun variations of the Euro Area housing-income ratio since the previous time series evidence suggests that the housing-income ratio predicts the factor that explains the cross-section of foreign currency returns. And indeed, I find a clear pattern. Low exposure to the housingincome ratio is associated with high excess returns on foreign currencies and vice versa, reflecting the negative relation between the housing-income ratio and the carry trade premium.

The remainder of this paper is organized as follows. Section two introduces the Lustig et al. (2008) framework and presents results from the cross-sectional asset pricing exercise. Section three summarizes the relation between incomplete consumption risk sharing and asset risk premia and the corresponding empirical results. Section four concludes.

\section{Common risk factors in currency markets: Euro Area evidence}

The uncovered interest rate parity condition states that exchange rates should depreciate according to the interest rate differential vis-à-vis the base country. Empirically, this condition is rarely fulfilled with the exception of high inflation rate countries (Fama (1984), Bansal and Dahlquist (2000)). High interest rate currencies do not depreciate as much as expected from 
the difference between foreign and home interest rates and low interest rate currencies depreciate by more than expected from interest rate differentials. This finding might be due to the presence of extra risk premia for investments in foreign currencies (see e.g. the survey in Engle (1996)).

After the formation of currency portfolios according to interest rate differentials, Lustig and Verdelhan (2007) show that consumption-based versions of the capital asset pricing model explain the cross-section of annual foreign currency returns from the perspective of the U.S. investor.

Lustig et al. (2008) argue that the currency portfolios themselves provide all the information about systematic sources of risk that is needed to rationalize cross-sectional differences in average currency portfolio excess returns. They formulate a model that features the average currency portfolio return, the "dollar risk premium” and the return difference between the high and low interest rate differential sorted portfolio ${ }^{2}$, the "carry trade premium” as pricing factors. The second factor significantly explains the cross-section of foreign currency portfolio returns at monthly frequency from the perspective of U.S., UK, Swiss and Japanese investors. This paper applies this two factor model to foreign currency portfolios from the perspective of a Euro Area investor.

\subsection{Data and portfolio formation}

The sample period of this study runs from the first quarter of 1980 to the first quarter of 2007Q1. Currrency portfolios are formed with respect to a country’s interest rate differential vis-à-vis the Euro Area in the previous period. Currency excess returns are defined as $\varphi_{t+1}^{i}=i_{t}^{i}-i_{t}^{€}-\Delta e_{t+1}^{i}$ with $\Delta e_{t+1}^{i}$ the ECU/Euro exchange rate of country $i, i_{t}^{i}$ a short-term interest rate of country $i$ and $i_{t}^{\epsilon}$ the Euro Area short-term interest rate. Portfolio excess returns

\footnotetext{
${ }^{2}$ Lustig et al. (2008) use forward rates to construct currency portfolios but show that their results also pertain to interest rate sorted portfolios as in Lustig and Verdelhan (2007) since covered interest rate parity holds.
} 
are arithmetic averages of the individual currency excess returns. As in Lustig et al. (2008), I form six portfolios that are rebalanced every quarter. Hence, portfolio 1 always contains the low interest rate differential countries and portfolio 6 the currencies from countries with highest interest rates. The sample contains the following countries: Australia, Canada, Chile, China, Colombia, Czech Republic, Denmark, Egypt, Hong Kong, Hungary, India, Indonesia, Israel, Japan, Jordan, Korea, Malaysia, Mexico, Morocco, New Zealand, Norway, Pakistan, Peru, Philippines, Poland, Russia, Singapore, South Africa, Sri Lanka, Sweden, Switzerland, Thailand, Turkey, UK, USA and Venezuela. I employ a GDP weighted average interest rate of the Euro Area countries as Euro Area short-term interest rate, national 3-month treasury bills or money market rates and the respective Euro/ECU exchange rates of various countries. Euro exchange rates are available from the ECB website. Source for all the remaining data is the IMF’s Financial Statistics.

Table 1 reports annualized mean returns, standard deviations and the Sharpe ratio of the six currency portfolios in percentage points. Clearly the low interest rate currencies in portfolio 1 deliver the lowest returns and the high interest rate currencies in portfolio 6 the highest excess returns. Portfolio 3 seems to be an outlier since it offers the second highest returns. Apart from that exception, however, currency excess returns are monotonically increasing with the interest rate differential. This finding is consistent with the portfolio characteristics in Lustig and Verdelhan (2007) and Lustig et al. (2008).

Hence, I am able to construct the two pricing factors: the average return on these portfolios, the "Euro Premium", as well as the return difference between the portfolios 6 and 1, the “carry trade premium”. The average Euro Premium, henceforth abbreviated $R^{F X}$, is about -0.91 percentage points per annum, the average carry trade premium, henceforth abbreviated $H M L^{F X}$, is roughly 6.73 percentage points per annum. 


\subsection{The cross-section of foreign currency portfolio returns}

The cross-sectional empirical results of this paper are grounded in the stochastic discount factor representation of the most basic form of an asset pricing model, i.e.

$$
P_{t}^{i}=E_{t}\left[\beta \frac{u^{\prime}\left(C_{t+1}\right)}{u^{\prime}\left(C_{t}\right)} X_{t+1}^{i}\right]
$$

which arises naturally from the first-order conditions of an investor's utility maximization problem with $P_{t}^{i}$ the price of asset $i$ and $X_{t+1}^{i}$ the corresponding payoff. $E_{t}$ is the expectation operator conditional on time $\mathrm{t}$ information, $\beta$ is the subjective discount factor and $u^{\prime}(C)$ denotes the first derivative of the utility function $u(C) . C_{t}$ represents consumption at time t. Equivalently, gross returns, $\frac{X_{t+1}^{i}}{P_{t}^{i}}$, obey

$$
1=E_{t}\left(M_{t+1} R_{t+1}^{i}\right)
$$

with $M_{t+1} \equiv \beta \frac{u^{\prime}\left(C_{t+1}\right)}{u^{\prime}\left(C_{t}\right)}$ the stochastic discount factor (SDF) and $R_{t+1}^{i}$ the gross return on asset or portfolio $i$. Constantinides (1990) points out that all asset pricing models should proxy the intertemporal marginal rate of substitution of consumption (IMRS), $\frac{u^{\prime}\left(C_{t+1}\right)}{u^{\prime}\left(C_{t}\right)}$. Therefore, the log-linear version of the SDF under consideration in this paper takes the form

$$
m_{t+1}=a-b_{R F X} r_{t+1}^{F X}-b_{H M L F X x} h m l_{t+1}^{F X}
$$

with the constant, $a$, the logarithmic Euro premium, $r_{t+1}^{F X}$, and the logarithmic carry trade premium, $h m l_{t+1}^{F X}$. This paper considers the log-linear version of equation (6) for excess returns applied to the currency portfolio excess returns

$$
0=E_{t}\left(m_{t+1} \varphi_{t+1}^{i}\right)
$$

Plugging (3) into (4), we obtain

$$
0=E_{t}\left(\left(a-b_{R F X} r_{t+1}^{F X}-b_{H M L F X} h m l_{t+1}^{F X x}\right) \varphi_{t+1}^{i}\right)
$$


which naturally suggests to use the generalized methods of moment (GMM) framework proposed by Hansen (1982) in order to assess which of the two factors in question helps to price the asset returns under consideration. The GMM procedure then amounts to use pricing errors for the individual assets as moment conditions and choose the parameters of the SDF, the $b$ s, that relate the pricing factors with the asset returns such that the pricing errors are minimized.

Pricing errors for a given parameter vector, $b$, obey

$$
u_{t}(b)=\left(a-b_{R F X} r_{t+1}^{F X}-b_{H M L F X} h m l_{t+1}^{F X}\right) \varphi_{t+1}^{i}
$$

Defining the sample mean of the pricing errors as $g_{T}(b)=\frac{1}{T} \sum_{t=1}^{T} u_{t}(b)$ with $T$ the number of time series observations, then the GMM estimation minimizes a quadratic form of pricing error sample means such that $\hat{b}=\arg \min \left(g_{T}(b)^{\prime} W g_{T}(b)\right)$ for the weighting matrix $W$.

I apply a two-step procedure for that purpose and use the identity matrix as weighting matrix in the first step to obtain the estimates and use the efficient Newey-West (Newey and West (1987)) corrected weighting matrix with optimal number of lags to obtain robust standard errors.

In order to assess what factors are actually priced, I estimate the beta representation of equation (2) via the Fama-MacBeth cross-sectional regression (Fama and MacBeth (1973)).

The beta representation can be easily derived by exploiting $E(X Y)=E(X) E(Y)+\operatorname{cov}(X, Y)$, such that

$$
E_{t}\left(R_{t+1}^{i}\right)=\frac{1}{E_{t}\left(M_{t+1}\right)}+\left(\frac{\operatorname{cov}\left(R_{t+1}^{i}, M_{t+1}\right)}{\operatorname{var}\left(M_{t+1}\right)}\right)\left(-\frac{\operatorname{var}\left(M_{t+1}\right)}{E_{t}\left(M_{t+1}\right)}\right)
$$

which can be summarized to

$$
E_{t}\left(R_{t+1}^{i}\right)-R_{t}^{f}=\beta_{M}^{i} \lambda_{M}
$$


with $R_{t}^{f}=\frac{1}{E_{t}\left(M_{t+1}\right)}$, the risk-free rate, $\beta_{M}^{i}=\frac{\operatorname{cov}\left(R_{t+1}^{i}, M_{t+1}\right)}{\operatorname{var}\left(M_{t+1}\right)}$, the regression coefficient of excess return $i$ on the discount factor, representing the asset-specific quantity of systematic risk, and $\lambda_{M}=-\frac{\operatorname{var}\left(M_{t+1}\right)}{E_{t}\left(M_{t+1}\right)}$ interpreted as the price of risk.

Given the pricing kernel in equation (3) and the notation for currency excess returns, equation (8) collapses to

$$
\varphi_{t+1}^{i}=\beta_{R F X}^{i} \lambda_{R F X}+\beta_{H M L F X}^{i} \lambda_{H M L F X}
$$

in which $\lambda s$ represent the prices and $\beta s$ the asset-specific exposure to the respective risk factors. The first stage of the Fama-MacBeth cross-sectional regression is a time series regression of the currency portfolio excess returns on the risk factors and a constant to obtain the $\beta$ s , i.e.

$$
\varphi_{t+1}^{i}=\mu+\beta_{R F X}^{i} r_{t+1}^{F X}+\beta_{H M L F X}^{i} h m l_{t+1}^{F X}+\varepsilon_{t+1}^{i}
$$

The second step of the Fama-MacBeth regression requires to run cross-sectional regressions of the currency returns on their betas at each point in time, i.e.

$$
\varphi_{t}^{i}=\lambda_{R F X} \hat{\beta}_{R F X}^{i}+\lambda_{H M L F X} \hat{\beta}_{H M L F X}^{i}+v_{t}^{i}, \forall t
$$

not taking account of a constant since we deal with excess returns.

The main results reported in table 2 are easily summarized. The GMM estimates in panel A of table 2 show that the $h m l^{F X}$ factor helps to price the currency portfolio returns under study given the presence of $r^{F X}$. Consistent with this finding, panel B displays that $h m l^{F X}$ is also the only priced factor in the Fama-MacBeth cross-sectional regressions. Its risk price estimate is statistically significant according to the Shanken (1992) corrected t-statistics and within theoretically plausible values. As the pricing factors under study are returns, equation (8) could be applied to the respective pricing factor itself. A regression of the pricing factor on itself would give a regression coefficient of one, such that the mean excess return on that 
factor should equal its estimated risk price. Here, the estimated risk price is 5.68 percentage points p.a. The actual mean return is around 6.70 percentage points p.a. Hence, this condition seems to be roughly fulfilled. In addition, around 60 percent of the cross-sectional variation in average currency excess returns is explained in the Lustig et al. (2008) model.

The empirical success of this two factor model inevitably raises the question what kind of risks the $h m l^{F X}$ factor mirrors. The next section suggests a possible explanation.

\section{Incomplete consumption risk sharing and common factors in currency markets}

The basic idea of the consumption risk sharing literature is that consumers desire to insulate their consumption stream from idiosyncratic income shocks. One way to buffer idiosyncratic income shocks is to borrow and lend. This credit channel seems to be particularly important for households. However, households' access to credit markets varies over the business cycle (e.g. Gertler and Gilchrist (1994)). This observation is the point of departure of Lustig and van Nieuwerburgh (2005, 2006,a,b). They assess the implications of undiversified, idiosyncratic consumption risk for the risk premium on asset markets. Lustig and van Nieuwerburgh (2005) model an economy in which households face common and idiosyncratic income shocks. Idiosyncratic income shocks can be smoothed through borrowing and lending. Loans are only granted on the basis of collateral. The more collateral available in this economy the higher the number of households that are able to insure against idiosyncratic income shocks. In Lustig and van Nieuwerburgh (2005, 2006a,b) the ratio of an economy's collateral wealth relative to wealth that is not accepted as collateral serves as a proxy for the tightness of credit constraints faced by households. When collateral assets are relatively scarce more households are bound by credit constraints. Hence the dispersion in consumption 
growth rates at the household and regional level increases (Lustig and van Nieuwerburgh (2006a)). In addition, households will demand higher risk premia when collateral wealth is relatively low because their ability to insure idiosyncratic consumption risk is limited (Lustig and van Nieuwerburgh (2006b)).

Empirically, Lustig and van Nieuwerburgh (2005) proxy the collateral to non-collateral wealth ratio by the ratio of housing to income reasoning that real estate is the prime example of collateral wealth while it is difficult to borrow only against income. They find the housingincome ratio to be cointegrated around a time trend. Short-run fluctuations of the housingincome ratio should reflect the temporary tightening or relaxation of households' credit constraints and are closely related to consumption dispersion across households and regions. Hence, as predicted by the model, the temporary variation in the housing-income ratio predicts expected risk premia on the market portfolio. Nitschka (2008) computes a Euro Area version of the housing-income ratio that displays very similar properties as its U.S. counterpart. Temporary variation in the Euro Area housing-income ratio is closely related to the cross-sectional dispersion in Euro Area countries' consumption growth rates. Nitschka (2008) uses this housing-income ratio to show that the Euro Area market return seems to be only appropriately approximated if the return on real estate is taken into account for the sample period from 1980Q1 to 2007Q1.

As the basic logic of incomplete consumption framework outlined above should apply to all asset risk premia, I employ the housing-income ratio from Nitschka (2008) to assess if the two risk factors under study, $r^{F X}$ and $h m l^{F X}$, are predictable by short-run variations in the Euro Area housing-income ratio. Evidence in favour of predictability would indicate that the factors capture macroeconomic sources of risk and would hence stress the risk based explanation for the empirical failure of the UIP condition mirrored in the presence of currency excess returns.

To gauge the plausibility of this argument, I run long-horizon regressions of the form: 


$$
x_{t, t+h}^{i}=\alpha+\beta_{h}^{i} h i_{t}+\varepsilon_{t+h}
$$

with $x_{t, t+h}^{i}$, either the Euro or carry trade premium at the time horizon from $t$ to $t+h$ for the sample period from the first quarter of 1980 to the first quarter of 2007. The forecast horizon $h$ is in quarters and $h i_{t}$ is the short-run variation in the housing-income ratio as calculated in Nitschka (2008). The ECB graciously provided me with the quarterly housing wealth and income series to construct $h i_{t}$.

Before presenting details of the results, it is worth to highlight potential pitfalls with regard to long-horizon regressions. One major point of concern is the small sample size which can lead to spuriously blown up t-statistics at long forecast horizons such that inference from longhorizon regression estimates may be misleading. One way to circumvent this issue is to forecast from a vector autoregressive representation (VAR) and calculate long-run statistics from the short-run VAR estimates as suggested by Hodrick (1992). Another worrisome point is the summation of logarithmic one-period returns. Even though white noise in theory, Valkanov (2003) shows that concatenating logarithmic one-period stock returns leads to almost unit root processes in the long-run and hence spurious regression results. Valkanov suggests an adjustment to the conventional t-statistic to overcome this obstacle. Finally, longhorizon regressions should be regarded with healthy scepticism if the regressor is persistent which causes biased estimates (Stambaugh (1999)).

Therefore, I follow Hoffmann (2007) and simulate critical values of the Valkanov corrected tstatistics at the different forecast horizons. Since one-period, here quarterly, returns should be i.i.d., the sum of one-period returns should be white noise as well. So, one only needs to generate white noise random numbers in the sample size under consideration and sum them up over the forecast horizon to regress this artificial, theoretically sound "return” series on the predictive variable and store the respective absolute value of the t-statistic. This approach thus takes account of small sample size, persistence of the regressor and shows what the critical 
values of the t-statistic should be under these circumstances given the dependent variable is theoretically sound. Repeating this procedure sufficiently many times and calculating the value of the t-statistic for the significance level at which the null hypothesis is tested should give a good indication of the predictor's true forecasting.

Table 3 reports Newey-West (Newey and West (1987)) corrected t-statistics in parenthesis as well as Valkanov (2003) corrected t-statistics in brackets ${ }^{3}$ below the regression estimates. Asterisk next to the respective t-statistic signals predictability at the 95\% confidence level.

Again, the results are easily summarized. The short-run variation in the housing-income ratio seems to be a powerful predictor of the carry trade premium. The carry trade premium, $h m l^{F X}$, is predicted best at the business cycle frequency at time horizons from 12-20 quarters according to the Valkanov corrected t-statistic and from 8-24 quarters according to the Newey-West corrected t-statistics. $r^{F X}$ is not predictable. A temporarily high $h i_{t}$ predicts a low carry trade premium and vice versa. Remember that high $h i_{t}$ is associated with low consumption dispersion and hence little uninsured consumption risk. The predictability exercise thus mirrors that $h m l^{F X}$ perfectly fulfils the predictions of the incomplete consumption risk sharing framework for asset risk premia.

This finding reveals that $h m l^{F X}$ truly is a risk premium, i.e. exposure to $h m l^{F X}$ is equivalent to exposure to macroeconomic risks as mirrored in fluctuations of the housing-income ratio. In order to emphasize this point, I sort currency excess returns with respect to their exposure to $h i_{t}$ using a rolling window regression at data t of the individual countries' currency excess returns on $h i_{t}$ with a time window of 12 quarters. As $h i_{t}$ is negatively related to $h m l^{F X}$, one should expect that high $h i_{t}$ exposure currencies deliver low returns while low $h i_{t}$ exposure currencies should offer the highest returns. Table 4 summarizes the mean returns, standard

\footnotetext{
${ }^{3}$ The Valkanov corrected t-statistics are obtained after 5000 repetitions of long-horizon regressions of the artificially generated returns series on short-run variation in the housing-income ratio. The critical values are not materially affected letting the number of repetitions vary between 1000 to 20000 .
} 
deviation as well as the Sharpe ratio of these $h i_{t}$ sensitivity sorted currency portfolios. The pattern is clearly visible. Currencies with low/negative exposure to $h i_{t}$ offer the highest excess returns and vice versa. The portfolio returns are almost monotonically decreasing with the exposure to short-run variation in the Euro Area housing-income ratio.

\section{Conclusions}

This paper shows that a recently proposed two-factor model to explain cross-sectional differences in excess returns on foreign currency portfolios is successful when confronted with currency returns from the perspective of a Euro Area investor. The factor that is priced in foreign currency returns mimics the typical carry trade: borrowing in low interest rate currencies and investing in high interest rate currencies. Exploiting the implications of incomplete consumption risk sharing for asset risk premia, this paper demonstrates that the carry trade premium is clearly compensation for macroeconomic risks. Times of high amounts of uninsured consumption risk in the Euro Area are associated with an expected increase in the carry trade premium. 


\section{References}

Bansal, R., Dahlquist, M. (2000), "The Forward Premium Puzzle: Different Tales from Developed and Emerging Markets", Journal of International Economics 51(1), 115-144.

Constantinides, G. M. (1990), "Habit Formation: A Resolution of the Equity Premium Puzzle”, Journal of Political Economy 98, 519-543.

De Santis, R., Fornari, F. (2008), “Does Business Cycle Risk Account for Systematic Returns from Currency Positioning? The International Perspective”, ECB working paper

Engel, C. (1996), "The forward discount anomaly and the risk premium: A survey of recent evidence", Journal of Empirical Finance, 3, 123-192.

Fama, E. F. (1984), "Forward and Spot Exchange Rates", Journal of Monetary Economics, 14, 319-338.

Fama, E. F., MacBeth, J.D. (1973), “Risk, Return and Equilibrium: Empirical Tests”, Journal of Political Economy 81, 607-631.

Gertler, M., Gilchrist, S. (1994), „Monetary Policy, Business Cycles, and the Behaviour of Small Manufacturing Firms”, Quarterly Journal of Economics 109, 309-340.

Hansen, L. P. (1982), "Large sample properties of Generalized Method of Moments estimators”, Econometrica 50, 1029-1054.

Hodrick, R. J. (1992), "Dividend Yields and Expected Stock Returns: Alternative Procedures for Inference and Measurement”, Review of Financial Studies 5, 357-386.

Hoffmann, M. (2007), "Proprietary Income, Entrepreneurial Risk and the Predictability of U.S. stock returns”, unpublished working paper, University of Zurich

Lustig, H., Roussanov, N. and Verdelhan, A. (2008), "Common Factors in Currency Markets”, working paper UCALA, Boston College and Wharton School.

Lustig, H., van Nieuwerburgh, S. (2005), „Housing Collateral, Consumption Insurance and Risk Premia”, Journal of Finance 60, 1167-1219.

Lustig, H., van Nieuwerburgh, S. (2006a), „How much does Household Collateral constrain Regional Risk Sharing?”, working paper UCLA and NYU Stern

Lustig, H., van Nieuwerburgh, S. (2006b), „Can Housing Collateral explain Long-Run Swings in Asset Returns?”, working paper UCLA and NYU Stern

Lustig, H, Verdelhan, A. (2007), “The Cross-Section of Foreign Currency Risk Premia and Consumption Growth Risk”, American Economic Review 97, 89-117.

Newey, W. K., West, K.D. (1987), “A simple positive semi-definite heteroskedasticity and autocorrelation consistent covariance matrix”, Econometrica 55, 703-708. 
Nitschka, T. (2008), "The Risk Premium on the Euro Area Market Portfolio: The Role of Real Estate”, IEW working paper 385.

Shanken, J. (1992), “On the estimation of beta-pricing models”, Review of Financial Studies 5, 1-33.

Stambaugh, R. F. (1999), “Predictive regressions”, Journal of Financial Economics 54, 375421.

Valkanov, R. (2003), "Long-horizon regressions: theoretical results and applications", Journal of Financial Economics 68, 201-232. 


\section{Tables}

Table1: Descriptive Statistics of foreign currency excess returns

\begin{tabular}{lllllll}
\hline \hline & 1 (Low) & 2 & 3 & 4 & 5 & 6 (High) \\
\hline $\begin{array}{l}\text { mean } \\
\text { return }\end{array}$ & -4.12 & -2.65 & 0.65 & -2.37 & 0.47 & 2.61 \\
\hline $\begin{array}{l}\text { Standard } \\
\text { deviation }\end{array}$ & 15.68 & 16.46 & 15.88 & 18.44 & 18.97 & 24.68 \\
\hline $\begin{array}{l}\text { Sharpe } \\
\text { Ratio }\end{array}$ & -0.27 & -0.16 & 0.04 & -0.13 & 0.03 & 0.11 \\
\hline
\end{tabular}

Notes: This table provides annualized mean returns, standard deviations and the Sharpe ratio for excess returns on foreign currencies sorted into portfolios according to the respective interest rate differential with the Euro Area. The sample period spans the time from first quarter of 1980 to the first quarter of 2007. Excess returns on foreign currencies are defined as $\varphi_{t+1}^{i}=i_{t}^{i}-i_{t}^{\epsilon}-\Delta e_{t+1}^{i}$ with $\Delta e_{t+1}^{i}$ the ECU/Euro exchange rate of country $i, i_{t}^{i}$ a short-term interest rate (either 3-month money market rate or treasury bill) of country $i$ and $i_{t}^{\epsilon}$ the Euro Area short-term interest rate. Portfolio excess returns are arithmetic averages of the individual currency excess returns. Portfolios are rebalanced every quarter where portfolio 1 contains the currencies from countries with lowest interest rate differential vis-à-vis the Euro Area and portfolio 6 the countries with highest interest rate differentials. 
Table 2: GMM and risk price estimates from two-factor model

Panel A: GMM

\begin{tabular}{ccc}
\hline$b_{R F X}$ & $b_{\text {HMLFX }}$ & \\
-2.42 & 8.48 & \\
$(-1.12)$ & ${ }_{(4.60)}$ & \\
\hline & Panel B: Fama-MacBeth & $R^{2}$ \\
\hline$\lambda_{R F X}$ & $\lambda_{\text {HMLFX }}$ & 0.63 \\
-0.99 & 5.86 &
\end{tabular}

Notes: Panel A of this table shows parameter estimates, $b_{R F X}$ and $b_{\text {HMLFX }}$ from a GMM estimation of the two factor model proposed by Lustig et al. (2008) confronted with excess returns on foreign currencies from the Euro Area investor's perspective. T-statistics in parenthesis are Newey-West corrected (Newey and West (1987)).

Panel B displays annualized risk price estimates in percentage points from a Fama-MacBeth cross-sectional regression (Fama and MacBeth (1973)). The Fama-MacBeth regression requires two steps. In the first step, the asset returns under study are regressed on the pricng factors in a simple time series regression to obtain their sensitivities (betas). The second step is a cross-sectional regression of the asset returns on the betas to obtain risk prices The tstatistics in parenthesis below the estimates are Shanken (1992) corrected to correct for the fact that the second stage regressors are generated in a time series regression.

The column $\mathrm{R}^{2}$ gives the cross-sectional $\mathrm{R}^{2}$ adjusted for the number of regressors. 
Table 3: Long-horizon regressions of RFX and HMLFX on hi

\begin{tabular}{|c|c|c|c|c|c|c|c|}
\hline & $h=1$ & $h=4$ & $h=8$ & $h=12$ & $h=16$ & $h=20$ & $h=24$ \\
\hline \multirow[t]{2}{*}{ RFX } & $\begin{array}{l}0.02 \\
(0.45)\end{array}$ & $\begin{array}{l}0.07 \\
(0.34)\end{array}$ & $\begin{array}{l}0.06 \\
(0.17)\end{array}$ & $\underset{(-0.16)}{-0.07}$ & $\begin{array}{c}-0.29 \\
(-0.60)\end{array}$ & $\underset{(-1.24)}{-0.54}$ & $\begin{array}{c}-0.96 \\
(-2.12)^{*}\end{array}$ \\
\hline & {$[0.04]$} & {$[0.03]$} & {$[0.02]$} & {$[-0.02]$} & {$[-0.06]$} & {$[-0.12]$} & {$[-0.20]$} \\
\hline$R^{2}$ & -0.00 & -0.00 & -0.00 & -0.00 & 0.00 & 0.03 & 0.09 \\
\hline \multirow[t]{2}{*}{ HMLFX } & $-{ }_{(-1.03)}^{0.07}$ & -0.39 & -1.11 & -1.93 & -2.51 & -2.63 & -2.80 \\
\hline & {$[-0.10]$} & {$[-0.14]$} & {$[-0.23]$} & {$[-0.46]^{*}$} & {$[-0.71]^{*}$} & {$[-0.53]^{*}$} & {$[-0.37]$} \\
\hline$R^{2}$ & 0.00 & 0.05 & 0.18 & 0.38 & 0.60 & 0.52 & 0.45 \\
\hline
\end{tabular}

Notes: This table reports estimates from long-horizon regressions of the form:

$$
x_{t, t+h}=\alpha+\beta^{h} h i_{t}+\varepsilon_{t+h}
$$

where $x$ denotes either the Euro premium, $r^{F X}$, or the carry trade premium, $h m l^{F X}$, at time horizon $t$ to $t+h$. The regressor, $h i_{t}$, is the temporary deviation from the long-term trend in the ratio of residential housing wealth and disposable income in the Euro Area as calculated in Nitschka (2008) The forecast horizon, $h$, is in quarters. T-statistics in parenthesis are NeweyWest corrected (Newey and West (1987)), t-statistics in brackets are Valkanov (2003) corrected. Both appear below the regressor estimates. Asterisk indicates significance at the 95\% confidence level according to the respective t-statistic. The row below the estimates reports the adjusted $R^{2}$ statistic. The sample spans the period from the first quarter of 1980 to the first quarter of 2007. 
Table 4: Descriptive Statistics of foreign currency excess returns sorted by exposure to housing-income ratio (rolling window regression, time window 12 quarters)

\begin{tabular}{lllllll}
\hline \hline & 1 (Low) & 2 & 3 & 4 & 5 & 6 (High) \\
\hline $\begin{array}{l}\text { mean } \\
\text { return }\end{array}$ & 1.33 & 0.71 & -2.02 & -2.79 & -2.01 & -6.89 \\
\hline $\begin{array}{l}\text { Standard } \\
\text { deviation }\end{array}$ & 9.95 & 7.60 & 8.08 & 8.54 & 9.57 & 14.06 \\
\hline $\begin{array}{l}\text { Sharpe } \\
\text { Ratio }\end{array}$ & 0.13 & 0.09 & -0.25 & -0.33 & -0.21 & -0.49 \\
\hline
\end{tabular}

Notes: This table provides annualized mean returns, standard deviations and the Sharpe ratio for excess returns on foreign currencies sorted into portfolios according to their respective exposure to the short-run variation in the housing-income ratio. The sample period spans the time from first quarter of 1980 to the first quarter of 2007. Excess returns on foreign currencies are defined as $\varphi_{t+1}^{i}=i_{t}^{i}-i_{t}^{\epsilon}-\Delta e_{t+1}^{i}$ with $\Delta e_{t+1}^{i}$ the ECU/Euro exchange rate of country $i, i_{t}^{i}$ a short-term interest rate (either 3-month money market rate or treasury bill) of country $i$ and $i_{t}^{\epsilon}$ the Euro Area short-term interest rate. Portfolio excess returns are arithmetic averages of the individual currency excess returns. Portfolios are rebalanced every quarter where portfolio 1 contains the currencies from countries with lowest exposure to temporary variation in the Euro Area housing-income ratio and portfolio 6 the countries with highest sensitivity to the housing-income ratio. 